\title{
Learner Understanding of Energy Degradation
}

\author{
Abigail R. Daane, Stamatis Vokos, and Rachel E. Scherr \\ Department of Physics, Seattle Pacific University, Seattle, WA 98119
}

\begin{abstract}
Learners' everyday ideas about energy often involve energy being "used up" or "wasted." In physics, the concept of energy degradation can connect those ideas to the principle of energy conservation. Learners' spontaneous discussions about aspects of energy degradation motivated us to introduce new learning goals into our K-12 teacher professional development courses. One of our goals is for learners to recognize that since energy degradation is associated with the movement of some quantity towards equilibrium, the identification of energy as degraded or free depends on the choice of the objects involved. Another goal is for learners to recognize that overall energy degradation occurs. We find that teachers' discussions contain productive ideas about energy degradation that demonstrate progress towards our goals. These include (1) the idea that degraded energy can be made useful and (2) the idea that making energy useful requires either effort or energy relocation.
\end{abstract}

Keywords: energy, second law of thermodynamics, conservation, degradation, professional development PACS: 01.40 Fk, 01.40 E-, 05.70-a

\section{INTRODUCTION}

Energy conservation is central both in a sociopolitical sense and in the study of physics, but the term has a different meaning in each context. In physics, energy conservation refers to the idea that the same total quantity of energy is always present in any closed system; energy is neither created nor destroyed. In the public consciousness, however, energy conservation refers to the idea that we have to guard against energy being wasted or used up; the energy available to serve human purposes is both created (in power plants) and destroyed (in processes that render it unavailable to us).

$\mathrm{K}-12$ teachers are in an unusual position in that they introduce both scientific concepts and social responsibility to young members of society. We ask teachers in our professional development to consider energy's degradation as a way to address sociopolitical concerns about energy in physics instruction. We see their responses as resources from which to build a sophisticated understanding of energy in physics and society, one that is both useful for K-12 teachers and their students, and responsible to corresponding canonical physics. This paper examines teachers' ideas about making energy useful and shows how those ideas are productively linked to energy degradation.

\section{THEORETICAL FRAMEWORK}

We take a constructivist perspective in which learners' ideas always have some seed of correctness; we attend to that sound thinking both out of respect for the learner as an intelligent person, and because it is the material out of which new growth occurs [1]. Prior and emerging ideas are seen as productive beginnings (or resources) in the learning process even if those ideas are misapplied in the new context [2]. In our study, we seek to identify and better understand resources that emerge organically in discussions that occur during a professional development course.

\section{PHYSICS OF ENERGY DEGRADATION}

To help learners connect their intuitive ideas to canonical physics content, we have begun to encourage discussions about degraded energy: energy that is not available for the production of work [3]. In order to avoid requiring our learners to integrate models of force and energy prematurely, we define degraded energy equivalently as energy unavailable for the process of mechanical energy transfer. For example, in a gasoline-powered car, the thermal energy that dissipates to the environment as the engine runs is degraded in that it can no longer be used to propel the car.

Energy degradation is associated with movement toward equilibrium in a quantity potentially associated with work (such as temperature, pressure, or concentration). When a partition is removed between a vacuum and a cube of gas, the gas will expand from the area of high concentration into the volume that was a vacuum. This expansion process reduces the pressure gradient between the two volumes and degrades the energy that was associated with the filled cube. The expansion also spreads energy more equitably through the system [4]. Energy spreads (within objects, to other objects, through space, by mixing, and in momentum space) in real, irreversible physical 
processes. This spread is accompanied by an increase in entropy [4]. In other words, energy spreading, energy degradation, the reduction of gradients, and entropy production are all features of real, irreversible processes. This co-occurrence prompts a degradationoriented statement of the second law of thermodynamics: Energy degrades in irreversible processes. A given quantity of energy is not degraded fully until all possible gradients associated with that energy are eliminated. Yet, for a given set of objects, energy can degrade with respect to the elimination of a particular gradient. That gradient will not reappear unless more outside energy is degraded to recreate it.

Energy degradation is defined relative to a specific set of objects. For example, thermal energy that accumulates in a car as a result of the engine running may be identified as degraded in the system consisting only of the car, because it cannot be used to propel the car. However, that same thermal energy may be identified as free in a system that includes the freezing temperature of the surrounding air - a system that has a temperature gradient not present in the car system, and that could, in theory, power some other process. Thus, degraded is not a property of units of energy; rather, it is a quality of the distribution of energy among interacting objects.

Energy that is available for the production of work (or mechanical transfer) is named free energy in physics, in the sense that it is available for use. Free energy is associated with a gradient in a quantity potentially associated with work (such as temperature, pressure, or concentration). The total energy in a system can be productively modeled as the sum of the degraded energy and the free energy. Though the total amount of energy in a closed system is unchanged regardless of what physical processes may take place, the amount of free energy decreases during many physical processes.

\section{RESEARCH CONTEXT}

In what follows, we examine an episode that highlights learners' ideas about energy degradation. The episode was selected from video records of professional development for K-12 physical and life science teachers offered through Seattle Pacific University as part of the Energy Project. On a biweekly schedule, approximately 10-18 teachers attend two-hour seminars on energy topics. In this instruction, learners identify the objects that interact in a given scenario and track the energy as it transfers among those objects. Based on the ideas from teachers in our courses and previous literature about learner understanding of energy and the second law of thermodynamics [5-7], we developed learning goals for our professional development that explicitly address energy degradation and the second law of thermodynamics. These learning goals aim to help K12 teachers make connections between instruction and urgent sociopolitical issues [8]. In this paper we share learners' ideas regarding two learning goals.

Goal 1: Since energy degradation is associated with the movement of some quantity towards equilibrium, learners should be able to show that the identification of energy as "degraded" or "free" depends on the choice of objects in the scenario. We would like learners to recognize that the introduction of a new object can change the energy from degraded to free, if the new object is not in equilibrium with the others. Another relevant learning goal relates to the second law of thermodynamics:

Goal 2: Learners should be able to identify the occurrence of overall energy degradation.

This is a statement of the second law of thermodynamics that we see as particularly appropriate for K-12 teachers and students.

\section{LEARNERS' DEGRADATION IDEAS}

Learners had the opportunity to discuss and develop their understanding of energy degradation in the context of two scenarios. First, learners discussed the energy involved in releasing a compressed piston (decreasing a pressure gradient). Second, they discussed the energy scenario of a wind turbine heating a house (decreasing the atmosphere's pressure and temperature gradients). After four seminars where learners discussed both scenarios in small group and whole class discussions, they were asked to reflect on their understanding of energy degradation. In the following, we describe a discussion between three learners' that provides insight into their ideas.

\section{Degraded Energy Can Be Made Useful}

Charlene describes her understanding of energy degradation and her objection to the idea that energy, once degraded, cannot be used again.

${ }^{\mathbf{1}}$ Charlene: I still don't, I can't wrap my brain around degraded energy.

${ }^{2}$ Donna: Can you tell us a little bit, I wasn't able to make it last time.

${ }^{3}$ Charlene: Just the idea that people have, who does- how do you know that it's been degraded? I mean how, you can't really measure, I understand the idea that once you have the energy out, I understand that it's no longer useful in this aspect, but that, I don't see how that can make it not useful in other areas. 
${ }^{4}$ John: I think that is what we were trying to define. We were trying to say, you need to define that. Because it may be degraded in one sense but-

${ }^{5}$ Donna: but it might be useful somewhere else.

${ }^{6}$ John: -not degraded. Yah, because it's not going away, it's just going somewhere else.

${ }^{7}$ Charlene: Yah, but that's not the impression that I got from what a lot of people were saying. The impression I got was that it was degraded so we can't gather it back up again and use it again. But how do we know we can't gather it back up again? Does it just like hang around and now I'm degraded and I've got to just sit here and-

${ }^{8}$ John: That's not the impression that I got at all.

Charlene begins by expressing confusion about the designation of degraded energy. When Charlene states "this aspect" in line 3, she points to the scenario of the compressed piston that pushes a block across the table. Her statement could be interpreted in at least two ways. She may be thinking that while the energy cannot be mechanically transferred in the piston scenario, that energy may become transferable if the scenario changes. Alternatively, she may be referring to what can be done with the energy in this scenario: after the energy is used for one purpose, it can't be used for that again, but could be used to for some other purpose without changing the scenario. In any case, Charlene's statement is consistent with the idea that degradation depends on the objects involved in a particular scenario (Goal 1). Even though Charlene has probably not yet achieved this learning goal in a robust sense, her statements suggest resources from which to build a sophisticated understanding.

Charlene has the impression that many people think that degraded energy cannot be "gathered back up again" or "used again." This is counter to her ideas about degradation. She has the right intuition that in many cases, energy that is degraded in a given system may not be degraded with respect to other gradients outside the system. However, Charlene does not discuss what it would take to gather it up again (i.e., recreate the original gradient) or whether overall degradation occurs. In other words, Charlene's statements suggest ideas consistent with Goal 1 (energy degradation depends on the objects involved) but not Goal 2 (overall energy degradation occurs).

Donna supports Charlene's idea about the relative nature of energy degradation using an example about cars:

${ }^{9}$ Donna: With newer technologies, we find better ways to reuse energy, like, in a hybrid car vs. a regular car, there's a lot of energy that's wasted that goes to braking and heating,

${ }^{10}$ Charlene: Yah, we talked about that too.

${ }^{11}$ Donna: Yah, we actually charge the batteries off of braking, so we are able to channel some of that energy back into something that's useful. So part of it is a leap of technology too, in terms of what we can do.

Donna's explanation about reusing energy in hybrid cars supports Charlene's ideas that energy can be made useful again. Donna states that "with newer technologies we find better ways to reuse energy," indicating that she recognizes that energy degradation depends on the objects involved. In this case, the status of the degraded energy can change by the inclusion of additional objects in a hybrid car (Goal 1).

\section{Making Energy Useful Requires Relocation}

John adds to the conversation by sharing his views about how energy degradation depends on the objects in the system. (This portion of the conversation occurs between the first and second excerpts.)

${ }^{12}$ John: My impression was, it's degradedremember when we did the house thing, you know with the perpetual motion machine thing. Were you here? Last time we had the scenario of a house that was run off a turbine and the turbine ran an electric-

${ }^{13}$ Donna: Oh okay, a generator to power the house?

${ }^{14}$ John: Right, and then we thought, why can't that be a closed system? As far as that system goes, the energy would be eventually being degraded in the sense that that system wouldn't work anymore. But that energy had to go somewhere, and I got the impression that it goes out, it goes somewhere in the universe, or somewhere in the earth, and it will eventually be recycled into some other useful purpose, but not that it was degraded in a permanent sense.

John uses the wind-powered heating system to support Charlene's idea that energy is not degraded in a "permanent sense" even though it is degraded in system of the house, generator, and immediate environment. John describes degradation as relative to the objects involved and dependent on the system, consistent with Goal 1.

When John states, "I got the impression that [energy] goes out, it goes somewhere in the universe, or somewhere in the earth, and it will eventually be recycled into some other useful purpose," he explains that degraded energy can become useful again if two conditions occur. First, the system must change. He explains that when the degraded energy interacts with the outside environment, then the energy will become useful again. This aligns well with Goal 1 in that he sees the introduction of a new object (the outside environment) as potentially changing the status of the degraded energy. 
John further specifies an additional condition that the energy will become useful when it goes "out" or "somewhere else," presumably meaning outside the original system. John is correct in thinking that degraded energy can be useful at a later time and/or in a different location. In another location, this energy may be introduced to new gradients. The status of the energy depends only on these gradients, not the location of the energy per se. John's description indicates his agreement with the idea that degradation depends on the system (Goal 1), and the beginnings of an understanding of the role of gradients.

John also responds to Donna's description of the thermal energy involved in the braking and heating of a car. He states,

${ }^{15}$ John: You mentioned the car idea, the degraded energy and technologies that recapture some of that but that's still defined as the energy usefulness within the car. But if it's outside of the car, what's to say that all that thermal energy doesn't become part of a weather system?

John describes the thermal energy as only degraded in reference to a particular set of objects, regardless of technology; he suggests that the energy could always become useful outside of that system.

From these statements we find that learners participate in productive conversations about the relative nature of energy degradation and identify how degraded energy can be useful in other contexts. The ability to define degradation within a system helps learners to recognize that energy can be either free or degraded depending on the choice of objects (Goal 1).

\section{Making Energy Useful Requires Effort}

Charlene, John and Donna do not identify the occurrence of overall energy degradation (Goal 2). However, they share ideas that provide a logical bridge to the second law of thermodynamics; they articulate that they must $d o$ something to make degraded energy useful again. For example, Charlene proposes that one would need to "gather [energy] back up." Donna states that "we are able to channel that energy back." John describes energy "recycled into some other useful purpose" and states that we can "recapture some of that [energy]." Gathering, recycling, recapturing, and channeling energy suggest that it takes effort to make energy useful again.

These ideas about effort required for gathering (recreating gradients) are productive resources connected to the second law of thermodynamics. They relate to intuitions about the spontaneity of processes and irreversibility: gathering energy back up doesn't just happen. Indeed, the act of recreating gradients causes more energy to become degraded overall in the process. Recognition of the effort required to remake a gradient is the first productive step towards Goal 2 (identifying overall occurrence of energy degradation).

\section{CONCLUSIONS AND FUTURE WORK}

In summary, teachers' discussions reveal productive ideas about the nature of energy degradation and the requirement of effort to recreate gradients. These ideas show learners developing an understanding that energy degradation depends on the objects involved. Additionally, these ideas are productive building blocks that bring them closer to an understanding of how energy degradation can be used for understanding the second law of thermodynamics.

In future professional development, we will draw on teachers' understanding that energy degradation depends on the system to encourage understanding of the role of gradients in the usefulness of energy. We aim to promote "Energy degrades" as a K-12 appropriate version of the second law of thermodynamics. We expect this version will enable teachers to relate their students' sociopolitical concerns to energy degradation in physics instruction.

\section{ACKNOWLEDGMENTS}

We are grateful to the Physics Education Research Group at Seattle Pacific University, especially A. D. Robertson and K. Gray, and also to B. D. Geller, V. Sawtelle, and C. Alvarado for substantive discussions. This work was supported in part by the National Science Foundation (DRL 0822342).

\section{REFERENCES}

1. E. Duckworth, "The Having of Wonderful Ideas" and other essays on teaching and learning, New York, NY: Teachers College Press, 1996.

2. D. Hammer, Cognition and Instruction, 15(4): p. 485529 (1997).

3. R. D. Knight, Physics for Scientists and Engineers, San Franscisco, CA: Pearson Addison-Wesley, 2008.

4. H. S. Leff, American Journal of Physics 64(10), 12611271 (1996).

5. S. Kesidou and R. Duit, Journal of Research in Science Teaching 30(1), 85-106 (1993).

6. R. Duit, "Energy conceptions held by students and consequences for science teaching" in Proceedings of the International Seminar "Misconceptions in Science and Mathematics", Ithaca, NY: Cornell University, 316321(1983).

7. J. Solomon, Getting to know about energy: In school and society, Bristol, PA: The Falmer Press, 1992.

8. A. R. Daane, S. Vokos, and R. E. Scherr, "Learner intuitions about energy degradation" (in preparation). 